Transactions of the VŠB - Technical University of Ostrava, Mechanical Series

No. 2, 2013, vol. LIX

article No. 1958

\title{
Vladimír GOGA* \\ FINITE ELEMENT MODEL OF THE STRAIN GAUGE FOR DETERMINING \\ UNIAXIAL TENSION

\begin{abstract}
KONEČNO-PRVKOVÝ MODEL TENZOMETRA PRE URČENIE JEDNOOSOVEJ NAPÄTOSTI
\end{abstract}

\begin{abstract}
Strain gauge is device used to measure the mechanical strains of solid bodies. Deformation of the strain gauge element causes changes its electrical resistance. This resistance change, usually measured using a Wheatstone bridge, is related to the strain by the quantity known as the gauge factor. When the stains are known, it is possible to determined state of stress at a point of measured body using generalized Hooke`s law and Mohr`s circle. Finite element analysis of strain gauge measurement using ANSYS software is subject of this article.
\end{abstract}

\section{Abstrakt}

Odporový tenzometer je elektronická súčiastka, ktorou sa merajú pomerné deformácie pevných telies. Deformácia tenzometra sa prejaví zmenou jeho elektrického odporu. Zapojením tenzometra do Wheatstonovho mostíka je možné tieto zmeny odporu zmerat'. Zmena odporu tenzometra je priamo úmerná pomernej deformácii meraného telesa. Ak sú pomerné deformácie známe, pomocou Hookovho zákona a Mohrových kružníc je možné určit' napätost' v bode telesa. Predmetom tohto príspevku je simulácia tenzometrického merania pomocou metódy konečných prvkov v programe ANSYS.

\section{Keywords}

Finite element method, tensile test, strain gauge, Wheatstone bridge, ANSYS.

\section{INTRODUCTION}

Strength of the structures in mechanical and civil engineering is associated with calculation of mechanical stresses. Only tasks of the simple geometry can be solved analytically. Complex tasks are deal with various numerical methods, the most common method is finite element method (FEA finite element analysis). Verify the accuracy of the calculation is necessary to realize a practical measurement on a physical model. It is not necessary to measure the stresses at all points of the construction, but only at the critical points which are determined by FEA. The tension/compression stress is not measured directly, but is used Hooke's law, which describes the linear dependence of stress on the Young's modulus and strain in the region of elastic deformation. Therefore, the strains are measured directly and stresses are calculated from them. In engineering and construction, the basic materials of bearing structures are steel and concrete which elastic deformations are very small therefore the measured strains are necessary to somehow increase. To measure these strains are mainly used strain gauges [1].

Ing. PhD., Institute of Power and Applied Electrical Engineering, Faculty of Electrical Engineering and Information Technology, Slovak University of Technology in Bratislava, Ilkovičova 3, Bratislava, tel. (+421) 260291 687, e-mail: vladimir.goga@ stuba.sk 
Principle of strain gauge measurement is a change of the electrical resistance of the material due its deformation. Strain gauge is actually an electric wire of negligible cross section compared to its length and therefore the deformation is most pronounced precisely along its length (sensitive direction). Uniaxial strain gauge is shown in Fig. 1. Planar state of stress is determined by strain gauge rosettes (Fig. 2) which consist from three uniaxial strain gauges rotated by known angles. State stress at a point of measured body is then calculated with using generalized Hooke`s law and Mohr's circles $[2-4]$.
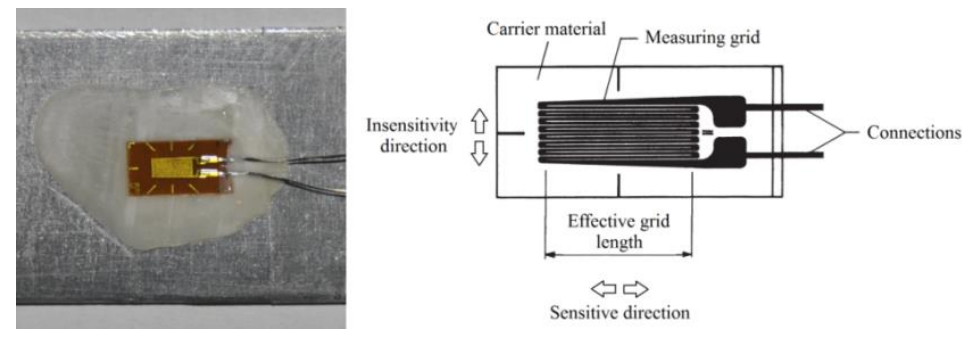

Fig. 1 Uniaxial strain gauge

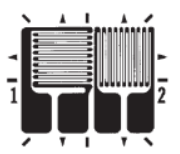

a)

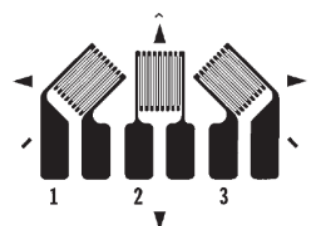

b)

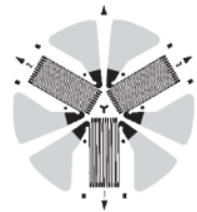

c)

Fig. 2 Basic rosette types, classified by grid orientation [1]:

a) $90^{\circ}$ tee, b) $45^{\circ}$ rectangular, c) $60^{\circ}$ delta

\section{PRINCIPLE OF THE STRAIN GAUGE MEASUREMENT}

Metallic foil strain gauge is commonly used. The metallic foil strain gauge consists of a grid of wire filament (a resistor) of approximately $25 \mu \mathrm{m}$ thickness, bonded directly to the strained surface by a thin layer of epoxy resin. Typical material for wire filament is a constantan (copper-nickel alloy). Strain gauge is attached to the surface of the measured structure with special glue, so that the surface deformation is transferred on the strain gauge. Surface deformation causes a very small change of the strain gauge resistance. To measure resistance change, the strain gauge is connected to the Wheatstone bridge. [1]

Wheatstone bridge is an electrical circuit used to measure an unknown electrical resistance by balancing two legs of a bridge circuit, one leg of which includes the unknown component [1]. Excitation voltage $U_{e}$ of the Wheatstone bridge is $1-10 \mathrm{~V}$. Quarter bridge is shown in Fig. 3. $R_{g}$ is the unknown resistance to be measured, $R_{1}, R_{2}$ and $R_{3}$ are resistors of known resistances. If the ratio of the two resistances in the known leg $R_{3} / R_{l}$ is equal to the ratio of the two in the unknown leg $R_{g} / R_{2}$, then the voltage between the two midpoints $(B$ and $D)$ will be zero and no current will flow through the galvanometer $U$. That means if $R_{g}$ is equal to the resistance of others resistors $R$ (all three resistors have the same resistance), output voltage $U$ is zero. Resistance change $\Delta R_{g}$ due to strain gauge deformation caused nonzero output voltage:

$$
U=\frac{1}{4} G F \cdot U_{e} \cdot \varepsilon \quad \Rightarrow \quad \varepsilon=\frac{4 \cdot U}{G F \cdot U_{e}}
$$

where:

$U \quad-$ is output voltage [V],

$U_{e}-$ is excitation voltage [V],

$\varepsilon \quad-$ is strain [-],

$G F$ - is gauge factor [-]. 


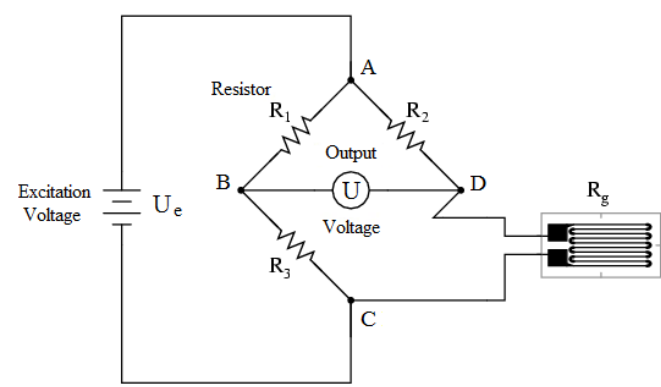

Fig. 3 Wheatstone bridge - quarter bridge

This resistance change $\Delta R_{g}$ is related to the strain by the quantity known as the gauge factor. Gauge factor for metallic strain gauge is typically around 2 and nominal resistance of resistors and strain gauge is 120 or $350 \Omega$. Gauge factor is defined [1]:

$$
G F=\frac{\Delta R_{g} / R_{g}}{\Delta L / L}=\frac{\Delta R_{g} / R_{g}}{\varepsilon},
$$

where:

$\Delta R_{g}$ - is gauge resistance change [ $\left.\Omega\right]$,

$R_{g} \quad$ is nominal gauge resistance $[\Omega]$,

$\Delta L \quad$ - is change in length [m]

$L \quad-$ is original length $[\mathrm{m}]$.

Finally, uniaxial tension/compression stress $\sigma$ is calculated by using Hooke's law:

$$
\sigma=E \cdot \varepsilon \quad \Rightarrow \quad \sigma=E \frac{4 \cdot U}{G F \cdot U_{e}}
$$

where:

$E \quad-$ is Young's modulus [Pa].

The accuracy of the strain gauge measurement is affected by several factors of which the most unfavorable is temperature sensitivity. Therefore half and full bridge is used instead quarter bridge. Half and full bridge can also increase value of output voltage. Various types of Wheatstone bridges for strain gauge measurements and their application samples are shown in Fig. 4.

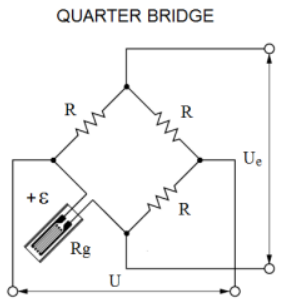

APPLICATION SAMPLE:

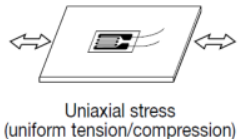

$U=\frac{1}{4} G F \cdot U_{\mathrm{e}} \cdot \varepsilon$

No temperature compensation

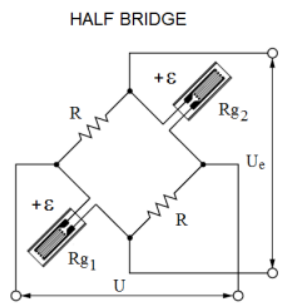

APPLICATION SAMPLE:

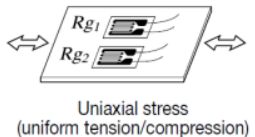

$U=\frac{1}{2} G F \cdot U_{\mathrm{e}} \cdot \varepsilon$

No temperature compensation

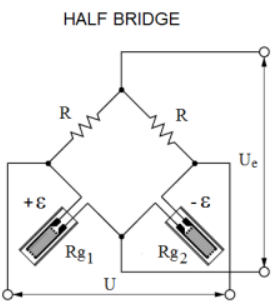

APPLICATION SAMPLE:

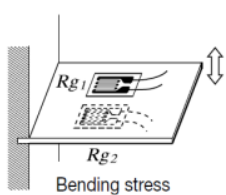

$U=\frac{1}{2} G F \cdot U_{\mathrm{e}} \cdot \varepsilon$

Temperature compensation

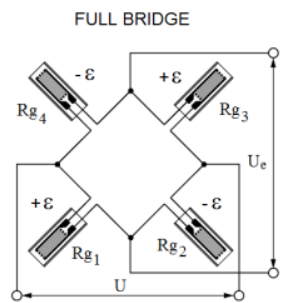

APPLICATION SAMPLE:

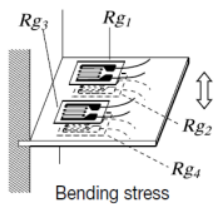

$U=G F \cdot U_{\mathrm{e}} \cdot \varepsilon$

Temperature compensation

Fig. 4 Types of Wheatstone bridges 
Basic principle of the strain gauge measurement was presented. Topic of this article is finite element analysis of strain gauge activity during tensile test. Electro-structural analysis was performed with software ANSYS.

\section{FINITE ELEMENT MODEL OF THE STRAIN GAUGE}

Geometry model of the strain gauge is represented just by solid wire filament with square cross section area $(S=20 \times 20 \mu \mathrm{m})$ and mid-length $42,6 \mathrm{~mm}$ (effective grid length is $3 \mathrm{~mm}$ ). Wire was meshed with element SOLID5. This element has a 3-D magnetic, thermal, electric, piezoelectric, and structural field capability with limited coupling between the fields [5]. Material of the strain gauge wire is constantan with properties: Young's modulus $162 \mathrm{GPa}$, Poisson's ratio 0,33 and resistivity $\rho_{C}=500 \mathrm{n} \Omega \cdot \mathrm{m}[6]$. Desired resistance $R$ for strain gauge is $120 \Omega$. For resistivity $\rho_{C}=500 \mathrm{n} \Omega \cdot \mathrm{m}$, the length of the constantan wire $l_{C}$ was calculated from:

$$
R=\rho_{C} \frac{l_{C}}{S} \Rightarrow l_{C}=\frac{R \cdot S}{\rho_{C}}=96 \mathrm{~mm},
$$

But length of our model is just $l=42,6 \mathrm{~mm}$. Therefore new resistivity for the model had to be determined:

$$
\rho=\frac{R \cdot S}{l}=1126,76 \mathrm{n} \Omega \cdot \mathrm{m}
$$

Ratio of lengths and resistivities must be equal: $96 / 42,6=1126,76 / 500=2,2535$.

New resistivity $\rho$ was controlled by electric simulation. Boundary condition at the wire ending surfaces was voltage $0 \mathrm{~V}$ and $5 \mathrm{~V}\left(U_{e}=5 \mathrm{~V}\right)$, respectively. Current $I$ passes through the wire is from Ohm's law (resistance of the wire $R=120 \Omega$ ):

$$
I=\frac{U}{R}=0,041667 \mathrm{~A} .
$$

Voltage distribution along the wire is shown in Fig. 5. For resistivity $\rho=1126,76 \mathrm{n} \Omega \cdot \mathrm{m}$ was current $0,04121 \mathrm{~A}$, what means wire resistance was $121,33 \Omega$. Resistivity has been modified to $\rho=1114,5$ $\mathrm{n} \Omega \cdot \mathrm{m}$ when current was 0,041665 A. Resistivity of the wire is then $120,005 \Omega$. Final resistivity for other simulations was therefore $\operatorname{chosen} \rho=1114,5 \mathrm{n} \Omega \cdot \mathrm{m}$.

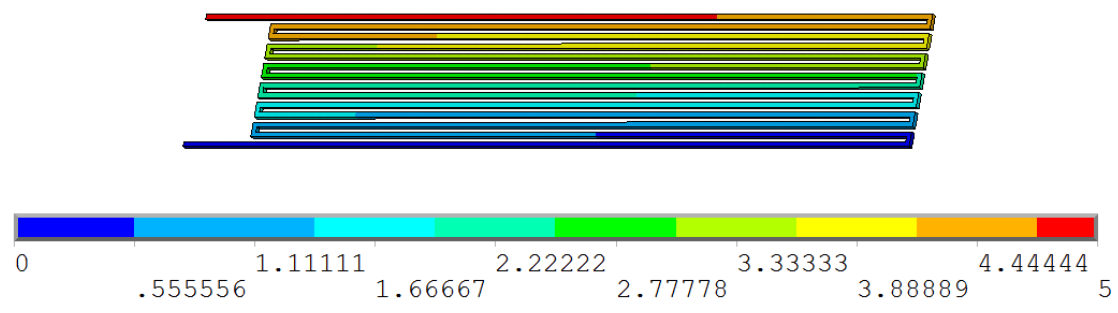

Fig. 5 Voltage result $[\mathrm{V}]$ in strain gauge model $\left(U_{e}=5 \mathrm{~V}\right)$

Validation of the strain gauge finite element model was performed by finite element simulation of the Wheatstone quarter bridge connection. Three resistors were created from element CIRCU124 [5] with nominal resistance $120 \Omega$. Wheatstone bridge circuit is shown in Fig. 6. Excitation voltage in circuit was $2,5 \mathrm{~V}$. Wire resistance was $120,005 \Omega$ and therefore measured output voltage was not zero, but $0,03 \mathrm{mV}$ (Fig. 6). This value must be subtracted from measured output voltage in the next tensile test simulations. This value of voltage can be considered as zero balance value. 


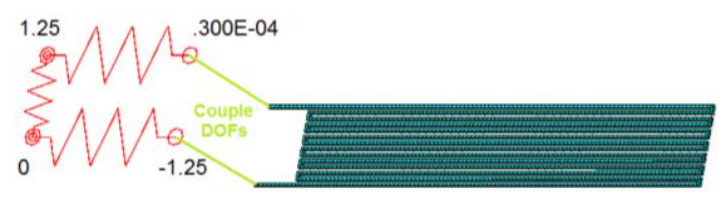

Fig. 6 Output voltage [V] for unloaded strain gauge finite element model (quarter bridge)

\section{SIMULATION OF THE STRAIN GAUGE MEASUREMENT}

Strain gauge measurement was simulated for tensile test. Sample was loaded by uniaxial pressure $p$ from 0 to $100 \mathrm{MPa}$. This pressure corresponds to measured tension stress in the sample. Dimensions of the tensile sample: $23 \times 2 \times 1 \mathrm{~mm}$. Sample material was steel with Young's modulus $E=210 \mathrm{GPa}$ and Poisson's ratio 0,3. Wire of strain gauge has no significant influence on the strength of the sample therefore the Young's modulus of wire was $1 \mathrm{~Pa}$ and Poisson's ratio 0,499. Resistivity of gauge wire was $\rho=1114,5 \mathrm{n} \Omega \cdot \mathrm{m}$. Geometrical model of tension sample was meshed with element SOLID285 [5]. Complex FEA model is shown in Fig. 7.
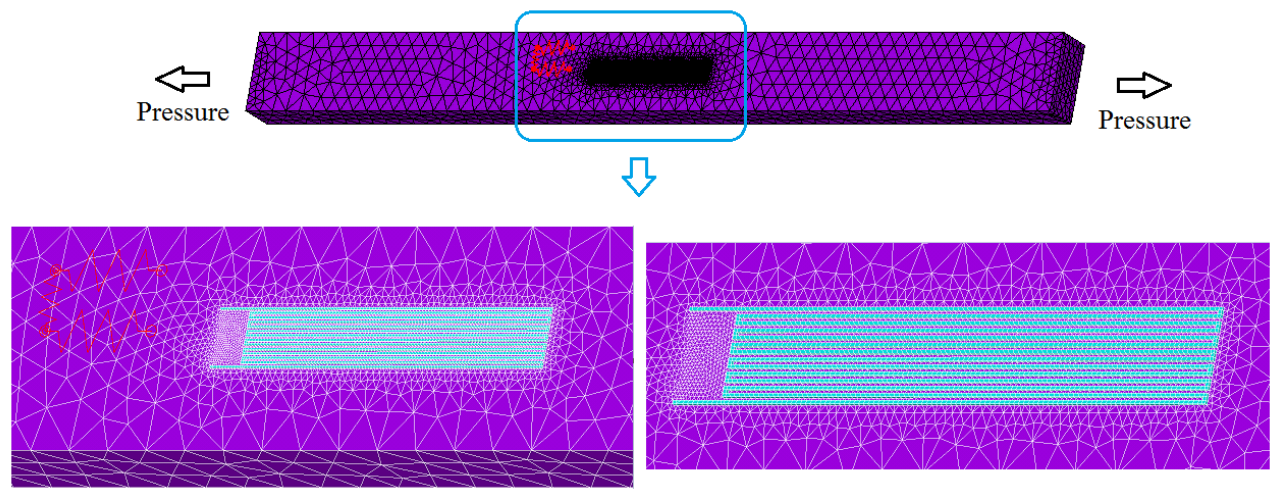

Fig. 7 Finite element model of the tensile sample with strain gauge

Structural and then electric analysis were performed for every load case. Excitation voltage in simulations was $U_{e}=2,5 \mathrm{~V}$ and we consider a zero balance voltage $U_{Z}=0,03 \mathrm{mV}$. Observed variable was measured voltage $U_{m}$. There is longitudinal strain and stress calculated from output voltage $U=U_{m}-U_{Z}$ using equation (1) and (3) in Tab. 1 . Gauge factor was $G F_{1}=2$. Fig. 8 shows results of longitudinal stress and strain for load case $p=40 \mathrm{MPa}$.

Tab. 1 Strain and stress from simulations $\left(G F_{1}=2\right)$

\begin{tabular}{|c|c|c|c|c|c|c|}
\hline$p[\mathrm{MPa}]$ & $U_{m}[\mathrm{mV}]$ & $U[\mathrm{mV}]$ & $\varepsilon\left[10^{-3}\right]$ & $\sigma[\mathrm{MPa}]$ & $\Delta \sigma[\mathrm{MPa}]$ & $\Delta \sigma[\%]$ \\
\hline 0 & 0,03000 & 0 & 0 & 0 & 0 & 0 \\
\hline 10 & 0,08853 & 0,05853 & 0,04682 & 9,8 & 0,2 & 1,7 \\
\hline 20 & 0,14706 & 0,11706 & 0,09365 & 19,7 & 0,3 & 1,7 \\
\hline 30 & 0,20559 & 0,17559 & 0,14047 & 29,5 & 0,5 & 1,7 \\
\hline 40 & 0,26412 & 0,23412 & 0,18730 & 39,3 & 0,7 & 1,7 \\
\hline 50 & 0,32265 & 0,29265 & 0,23412 & 49,2 & 0,8 & 1,7 \\
\hline 60 & 0,38118 & 0,35118 & 0,28094 & 59,0 & 1,0 & 1,7 \\
\hline 70 & 0,43971 & 0,40971 & 0,32777 & 68,8 & 1,2 & 1,7 \\
\hline 80 & 0,49824 & 0,46824 & 0,37459 & 78,7 & 1,3 & 1,7 \\
\hline 90 & 0,55677 & 0,52677 & 0,42142 & 88,5 & 1,5 & 1,7 \\
\hline 100 & 0,61531 & 0,58531 & 0,46825 & 98,3 & 1,7 & 1,7 \\
\hline
\end{tabular}




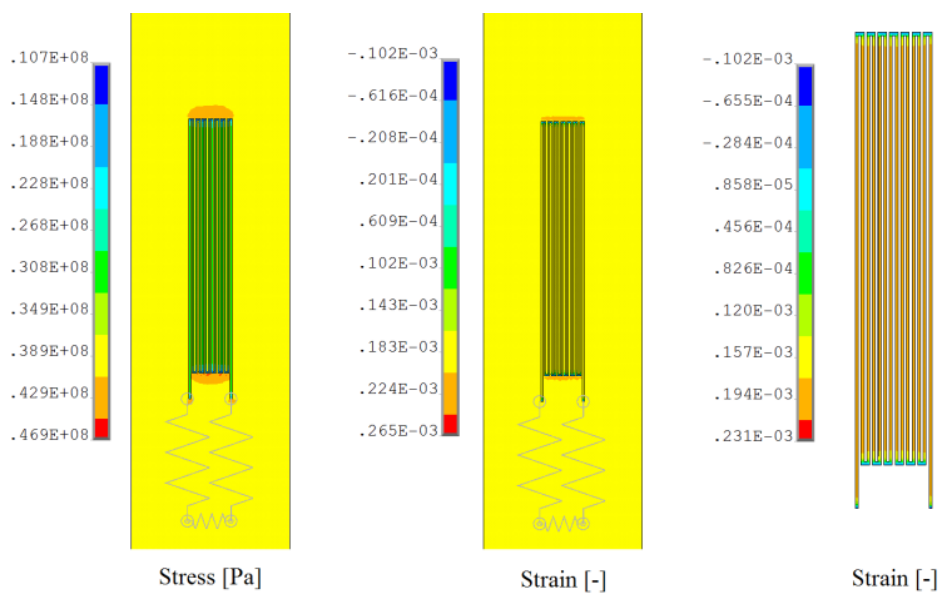

Fig. 8 Longitudinal stress and strain for load case $p=40 \mathrm{MPa}\left(G F_{l}=2\right)$

Percentage difference between applied pressure and stress result for each load case was $1,7 \%$. This error was caused by gauge factor $G F_{1}$. If the uniaxial stress is equal to applied pressure it is possible to calculate new gauge factor $G F$ from equation (3). Tab. 2 presents the stress results, when the new gauge factor $G F=1,967$ was used in simulations.

Tab. 2 Results from simulation with new gauge factor $\left(G F_{l}=1,967\right)$

\begin{tabular}{|c|c|c|c|c|c|c|c|c|c|c|}
\hline$p[\mathrm{MPa}]$ & 10 & 20 & 30 & 40 & 50 & 60 & 70 & 80 & 90 & 100 \\
\hline$\sigma[\mathrm{MPa}]$ & 10 & 20 & 30 & 40 & 50 & 60 & 70 & 80 & 90 & 100 \\
\hline$U[\mathrm{mV}]$ & 0,05853 & 0,11706 & 0,17559 & 0,23412 & 0,29265 & 0,35118 & 0,40971 & 0,46824 & 0,52677 & 0,58531 \\
\hline$G F[-]$ & 1,967 & 1,967 & 1,967 & 1,967 & 1,967 & 1,967 & 1,967 & 1,967 & 1,967 & 1,967 \\
\hline
\end{tabular}

\section{CONCLUSIONS}

Finite element analysis of strain gauge measurement was performed in software ANSYS. Strain gauge was modeled as a wire and its resistivity was calculated and adjusted according to the simulation. Voltage zero balance value was also determined from the electrical analysis. Finally, the finite element model of tension sample with strain gauge was created and tension test was simulated. Measured entity was output voltage in quarter Wheatstone bridge and strains and stresses in the sample were then calculated. Improvement of the results led to treatment of gauge factor. Strain gauge measurement simulation was coupling of structural and electrical analysis.

Modified finite element model with three gauges can be used for analysis the plane stress state at a point of structure under mechanical loading. This approach is useful to understand how the multiaxial stress state is determining using stain gauges.

\section{ACKNOWLEDGEMENT}

The work has been elaborated in support of Grant Agency VEGA, project No. 1/0534/12, Grant Agency KEGA, project No. 015STU - 4/2012 and by project APVV 0450 - 10.

\section{REFERENCES}

[1] HOFFMANN, K. An Introduction to Measurements using Strain Gages. Darmstadt: Hottinger Baldwin Messtechnik GmbH, 1989.

[2] BAUCHAU, O.A. \& CRAIG, J.I. Structural Analysis: With Applications to Aerospace Structures, Publisher: Springer, 2009, ISBN 978-90-481-2515-9 
[3] UGURAL, A.C. \& FENSTER, S.K. Advanced Mechanics of Materials and Applied Elasticity, Publisher: Prentice Hall, 2011, ISBN 978-0-13-707920-9

[4] TIMOSHENKO, S. \& GOODIER, J.N. Theory of Elasticity, McGraw-Hill Book Company, 1951

[5] ANSYS release 13, ANSYS Help: Element reference

[6] DAVIS, J.R. Copper and Copper Alloys, ASM International, 2001, ISBN 0-87170-726-8 